\title{
Distance Learning Solutions: Tools Used in Online Lessons
}

\author{
Aysel Zahid Khalilova \\ ${ }^{1}$ PhD, A Senior English Teacher, Azerbaijan State University of Economics (UNEC), The \\ Department of Languages, AZ-1000, Azerbaijan \\ ayselkhalilova1@gmail.com
}

Article History: Received: 10 November 2020; Revised 12 January 2021; Accepted: 27 January 2021; Published online: 5 April 2021

\begin{abstract}
The goals of distance education in higher institutions were clear for many years. Nowadays, owing to the global pandemic situation, higher educational institutions (HEI) have had to transition from conventional teaching modes to online modes. Although many top-ranked universities were prepared for this situation, others suffered, since their distance education department existed only in name; their activities were passive. However, COVID19 provided an opportunity for them to think deeply about their next steps.

In general, distance learning is an effective way of attracting adult learners. Furthermore, these learners desire a higher level of flexibility.

This article is based on the theoretical models essential to long-term plausibility and viability in the field of teaching practice. To evaluate the challenges and problems arising during online learning, the author has briefly reviewed all the contributions made to this field in the 21 st century.

In addition, the paper suggests tools and facilities for teachers and instructors in order to facilitate effective communication between teachers and students, both in and out of the virtual classroom. Researchers, postgraduate students and other readers will be able to use this paper to explore and exploit further modifications of research opportunities in this field.
\end{abstract}

Keywords

Distance Learning, Quality, Higher Education, Tool, Interactive learning

\section{Introduction}

Nowadays, distance education is at its peak for a better impact. The global pandemic situation has forced all educational entities to transition from traditional to online modes and HEI is no exception. University professors are concerned about the open and distance learning since it came into materialization, and they tried to give and implement various approaches in this field. The theoretical opinions by Sewart[12,13] stress the institution's continuity of concern for the quality of support of the student as the basis of the Open University's claimed success of high completion rates. Garrison [5] believed that the boundaries between distance education and traditional education will become increasingly blurred with the new communication technologies. However, the case Covid-19 has put a huge burden on educational institutions, and they tried to meet the current requirement of the world education, i.e. they targeted fully to educate their students remotely. For sure, universities with enough experience in distance education have not faced significant issues; however, inexperienced ones have faced hardships and tried to solve the problem in different ways.

\section{Research Background}

Distance education might seem a product of modern information technology, such as computers and the Internet; however, according to Harper, Kimberly, Chen, and Yen [7], the modern version is a revised reintroduction of an older method of education. The origin of distance education can be traced to the early $1700 \mathrm{~s}$ when correspondence courses were established in the United States and GreatBritain. Course materials, 
assignments, notes, tests, and feedback were delivered and exchanged through the postal service. [2]Distance education was integrated with the radio and television when these two mass communication media were invented at the beginning of the 20th century. Between 1980 and 1990, pre-recorded video and cassette recordings were heavily used in distance education. It was not until the 1990s - when computers became less expensive and more accessible to the public at large and the World Wide Web matured - that distance education was transformed into the version we are familiar with today [7].

This article aims to provide solutions to the challenges of online education as well as recommendations to teachers who are new to distance learning. Moreover, the article aims to find online learning tools that would facilitate student-centered lessons.

\section{Problem Statements \& Hypothesis}

Before the pandemic, no one in Azerbaijan could have imagined that any situation would necessitate having enough online teaching skills. All educational institutions began virtual education after April 2020. However, there were several drawbacks and a lack of clear knowledge about online teaching. Professors and teachers were unaccustomed to teaching remotely, and their teaching methodologies were set up to suit in-person classes; suddenly, sitting in front of computers and not having live learners created several hardships for the university as well as teachers. This condition necessitated research for solutions to these problems to find methods and tools to facilitate and accelerate the distant teaching process and post-crisis situation.

Lack of preparation for virtual lessons created specific problems for teachers and students. Distance learners demand and expect a high level of service when it comes to delivery of course material and exams, quick turnaround times for grading exams and assignments, and answering questions [4].

One of the main problems during distance education was technophobe professors; instructors who had few technological skills forgot how to teach classes innovatively during online lessons. Instead, they panicked and thought that teaching during the lockdown was not required. However, after some training, and with the help of the university administrator, they adapted to the situation. In the prevailing situation, another challenge also arose: How to motivate students for lessons because the attendance of learners decreased significantly during this period. Many educators have researched the students' involvement in the lessons. For example,Rekkedal[11] studied the role of the teacher for the betterment of the practices and the learner. No single factor appears to cause nonparticipation; however, individual student characteristics and life circumstances appear to have the greatest impact on participation [8]. To my mind, conducting research on the solutions to this problem and finding new tools that would innovatively supplement online lessons will help motivate students to learn during online lessons. Moreover, the findings will also help teachers increase the involvement of students in their virtual classes.

It is believed that this research will meet the needs of teachers who have recently begun teaching remotely. The found material will help them effectively conduct online lessons and, at the same time, it will help new online teachers to draw their students to remote lessons, increasing their interactivity and motivation.

The conditions arising from COVID-19 have affected Azerbaijan's HEI since only one or two private universities conducted their lessons virtually before the pandemic. This problem created a significant challenge for Azerbaijan's universities - one such educational institution (EI) is the Azerbaijan State University of Economics (UNEC). This 90-year-old university is the biggest EI in the Caucasus that specializes in economics. Classes at UNEC were taught by traditional methods before the lockdown, but the prevailing situation has prompted the university to improve its existing distance learning center. It was quite challenging for the staff at UNEC who had little or no experience in online lessons. Therefore, UNEC drew up a spontaneous strategic plan for virtual classes in March 2020. First, they created a UNEC external center, and the university's teachers began conducting classes online for 150 students in total. Each lesson lasted 40 minutes. However, the university researched the students and identified that the students found it difficult to learn within 40 minutes, especially in a class of 150 people. They also complained about the difficulty of understanding online lessons. Therefore, the strategy of teaching at least 80-150 students within 40 minutes was unsuccessful. After this experience, UNEC opened virtual studios in line with its real university cabinets and launched online lessons via 
the university's online system EDUMAN. In the latter experience, 1 teacher from 1 department went to Extern Centre and gave an online lesson instead of hislher department teachers to a faculty students at the same time, but later each teacher conducted their online lessons themselves, this was, of course, quite different from the previous one; however, there were several challenges in this case as well, such as having little experience in distance teaching, being unprepared for the distance learning situation, lack of motivation in students, lack of technological knowledge of professors above 60 years of age, intermittent loss of internet connection, lack of feedback from students, lack of experience in virtual classes and so on.

\section{Methods}

Online education provided more positive possibilities to many universities. It is an area which makes an access to an education that in other way, it would not be possible for some students. The standards are similar, while it is an alternative to traditional way. In order to keep these standards, assessments of the knowledge, teachers, programs, and schools are vital.

This chapter explains the methodological framework and procedures used to analyze the tools and methodologies used by foreign universities to find and analyze the best practices. For this, the author researched the question in 3 stages: First, she surveyed the UNEC teachers to find out the overall problems and challenges. She prepared 12 questions related to the problem and sent the questionnaires to the teachers who taught at her university. The teachers answered each question and they wrote their suggestions on the lessons which they held. After this survey, she made up 15 questions for students and sent the questionnaire to 150 UNEC students for feedback on their online lessons. Actually, almost all students showed their dissatisfaction about online lessons. Majority of students indicated that they preferred traditional lessons rather that online ones. They wrote about the speed of internet and their teachers' weak computer knowledge demotivated them. Furthermore, wrote that they could absorb only $50 \%$ of their teaching material and appreciated distant education as a waste of time. Finally, she researched global universities with experience in distance learning to identify how they solved the real challenges.

The sample from the questionnaire is as follows:

\section{Questions for teachers}

1. Did you have any experience in distance teaching?

2. What problems did you encounter during virtual classes?

3. How did you motivate students?

4. Did you use any tools and methodologies in your online lessons?

\section{Questions for students}

1. What problems did you have during online lessons?

2. Did you participate in all of your online lessons? If not, explain why.

3.How would you like to be evaluated?

After the internal survey with the teachers and students, the author conducted online meetings with the professors at the University of Sakarya (Turkey), the University of Manchester (England), and Boston University (US) and targeted to identify the following questions:

1. Which online platforms did you use/are you using before/after the pandemic?

2. Do you use any special tools and methodologies during online lessons?

3. How do you motivate students to participate in your online lessons?

4.How do you hold midterm exams?

5.Do you evaluate students daily?

During online lessons they discussed with experienced teachers the results of the research which had been made with teachers at UNEC and students. The professors of EU universities tried to give solutions and 
recommendations for teachers and they answered to the questions which have been given them about their online lessons.

Tuckman's Survey Research Method [14] indicates that survey research is "a particular kind of research that frequently appears in the educational milieu". Generally, survey research is used to collect data from a sampled population via constructed survey instruments to provide descriptive information about characteristics, perceptions, or attitudes about a chosen population. Survey research has two-fold usefulness: First, to gather information from a large sample of the population [6]; second, to present a generalization of that population, although self-reporting biases may be an issue [1]. In this study, three surveys, with simultaneous data collection, were used to investigate teachers' problems during online lessons, teaching styles, tools for online classes, and motivation of distance learners.

The author set up six questions on the form (four for teachers and two for students) as well as a blank space for teachers' and students' suggestions. The first two surveys were conducted via Google forms, and the best practices were discussed among the staff of the three international universities via Zoom.

\section{Results and Discussion}

About 450 teachers participated in the investigation.

The responses to the question "Did you have any experience in distance teaching?" were as follows:

About $78 \%$ of participants said that they did not have any experience in online lessons, $10 \%$ of instructors stated that they had taught remotely in previous years, and $12 \%$ of the teaching staff indicated that they had researched distance education, but had little experience in it.

Table 1. Teachers' Survey

\begin{tabular}{ccc}
\hline $\begin{array}{c}\text { Teachers' with no } \\
\text { experience in online } \\
\text { lessons }\end{array}$ & $\begin{array}{c}\text { Teachers previously } \\
\text { taught virtually }\end{array}$ & $\begin{array}{c}\text { Teachers who had enough } \\
\text { idea about online lessons, } \\
\text { but didn't practice }\end{array}$ \\
\hline $78 \%$ & $12 \%$ & $10 \%$ \\
\hline
\end{tabular}

Having no experience in online teaching, of course, made the educational process difficult for the teachers. Because they did not know how to cope with the problems, how to fix them during the lessons and at the same time, how to appeal students' attention.

The second question was about the problems teachers faced during virtual classes. The responses included students participating less, students with cameras switched off, sudden internet loss, and insufficient knowledge about online innovative methodologies. The teachers also complained about not being able to attract students to the virtual lessons. Some stated that giving students obligations, such as frequent quizzes and weekly or monthly performance evaluations during online classes could attract them. Unfortunately, only a few teachers wrote about tools and methodologies for online classes. It was clear from the survey that a majority of instructors were trying to become accustomed to teaching online and were not prepared for the situations of sudden internet loss. They did not have enough time to research innovative methodologies that would help them capture their students' attention. To fix these problems university should hold several trainings to educate its teachers because pandemic situation seems to continue for a long time. Or, to replace the technophobe teachers with the technophiles. I strongly believe that having the teachers who are unable or have difficulty in conducting lessons online can break a university reputation which is unacceptable. Any university should think deeply over it.

Students also mentioned their complaints via the survey. They were mainly dissatisfied with their Internet connection since $65 \%$ of UNEC students are from rural areas where internet speed is very low. Furthermore, they were dissatisfied because the lessons seemed boring. A total of $46 \%$ of students stated that they either did not participate or participated less in distance education. They mentioned that sometimes they could not correctly absorb the lesson; however, they had liked the same lesson when it was taught traditionally. 
Table 2. Students' Survey

\begin{tabular}{ccc}
\hline $\begin{array}{c}\text { Students who } \\
\text { never participated } \\
\text { in online lessons }\end{array}$ & $\begin{array}{c}\text { Students who } \\
\text { sometimes } \\
\text { participated }\end{array}$ & $\begin{array}{c}\text { Students } \\
\text { who always } \\
\text { participated }\end{array}$ \\
\hline $46 \%$ & $34 \%$ & $20 \%$ \\
\hline
\end{tabular}

After analyzing the teachers' and students' responses, the author researched the world's universities and connected with three universities. The UNEC team conducted a Zoom conference with the staff of these educational institutions. The staff shared their best practices and solutions that could be beneficial for UNEC. The COVID-19 pandemic affected the psychology of individuals and created much tension among people. More significantly, it had a huge impact on universities the world over. This condition was not unusual for educational institutions that had distance education facilities before the pandemic. However, universities like UNEC had to make some flexible decisions to continue disseminating their education. The frustrations resulting from problems with communication between student and academic institutions are factors of which distance education planners should be well aware [15]. This problem must be moderated by institutions providing a sense of personal involvement between the student and the institution. One way to solve this problem is through the use of tutors that communicate with students electronically, by phone, or personally at a personal contract program. Students believe that having a good tutor is vitally important in helping them get the most out of a course and to achieve a credit [9].

The pandemic allowed such universities the opportunity to make innovationsin their education. It is considered that the overall experience was quite successful despite the difficulties. Since nothing starts ideally in life, UNEC will achieve great success in the field of distance education.

As mentioned above, the problems related to students' motivation, including their lack of attention during lessons, not being active during lessons, and teacher-centered classes, are the main challenges to be solved in the next semester. First, it must be noted that it would be better to evaluate students' knowledge until the final exam this year.

The University of Sakarya (Turkey) holds weekly quizzes for their students, claiming that if a student studies a week's lessons, he/she will pass the weekly quiz; if a student does not attend, he/she will find it difficult to pass. The University of Manchester (UK) holds virtual lessons via its platform. They have 40-minute online lessons for one subject; also, the instructors record their videos using the Loom video recorder program. These videos are usually 4 or 5-minute long. The professors take the key terms in each topic and explain or analyze them in the video. They have stated that such videos help students understand the subject in depth.

The University of Boston has more interesting tools for conducting online lessons. They hold their weekly quizzes via Google classroom. Getting home assignments or the results of the quizzes via this program helps teachers maintain students' attention to the lessons. Moreover, they also implement "Google slides" and game programs such as "Kahoot" to motivate their learners.

Having an idea about the real challenges apart from those encountered by the universities, the author started to research tools that could be used during online lessons. They are as follows:

1. Using "Break Out Rooms" on the Zoom platform during the online classes. It makes it possible for teachers to do group work, pair work, or discussions during lessons. However, these rooms must be fixed before the Zoom conference. After that, if a teacher wants to conduct the lessons based on the pair work or group work, he/she sets the time limit and even assign people to groups during the lesson.

2. Creating interactive Google slides by choosing "Pear Deck" on the Google platform. Pear Deck provides interactive options when teaching remotely. Simply, gather students on a video call via Skype, Zoom, Google Meet, or Microsoft Teams and share your screen with an interactive Pear Deck presentation. Instead of presenting only informational slides, Pear Deck makes the slides interactive so that every student 
can respond to the questions or prompts right on their screens. Pear Deck slides help engage students and give informative assessments, regardless of the grade or subject. [18]

3. Conducting game-based lessons. Of course, people are fond of playing games, and such lessons would help a teacher to make his/her lesson creative and interesting. Instructors can take any part of their lessons and create their games. The programs for creating games are as follows:

https://www.baamboozle.com

https://www.brainpop.com

https://jeopardylabs.com

educandy.com

https://wheeldecide.com

https://oodlu.org

These programs can be useful for teachers who are enthusiastic about preparing and planning their lessons to motivate their students and maintain their attention during the lessons.

During the investigation universities that based their teaching mainly on distance education were observed to design the subject syllabus and textbook differently. It is believed that the syllabus and textbook format for distance learning must be researched and analyzed in detail. This step is crucial for the university since the lesson duration is half that of a traditional lesson, which means the units being covered during the traditional lessons must be reduced and set up for 40-minute classes.[19]

Activities that can be conducted out of the classroom must be researched in-depth. Programs such as Google Classroom or similar ones should be found and analyzed. Suitable programs could be beneficial for new teachers.

\section{Summary}

This study conducted to facilitate the teaching process during online lessons. During the research, data was provided that the innovative tools needed in the online lessons.

Findings and results in this research showed that methods and tools used in traditional methods differ from the online ones. Teachers realized that to attract students to the online lessons it is not only to sit in front of the computers and to introduce the presentation or to speak from the beginning of the lesson till the end. They have understood that online lessons are an art of teaching. It does not need only having computer skills, it does need also knowing different online and technological tools and effectively use it.

To sum, to motivate students to online lessons is a hard job, however, it can be solved with enthusiastic technological tools shown above. Some of the proposed tools have been experienced in different lessons by teachers. The most satisfied tool was breakout rooms on the Zoom program. By using it, students felt the similar effects that they got from the traditional lessons. In the breakout rooms, they discussed questions and topics in small groups, they shared their thoughts and opinions with each other. I feel that all other UNEC's professor staff will utilize these methods in their further online teaching life, however, in this term, another question for further research is arisen- how to motivate teachers to work remotely. Osman Titrek states that job satisfaction is crucial in educational life [3].To think over it, to find and to implement findings in the management of the staff will be beneficial for all HEI.

\section{References}

[1]. Bell, S. (1996). Learning with Information Systems: Learning Cycles in Information Systems Development. New York: Routledge.

[2]. Bonnie Armstrong, Hong Gao, E Shen,(2002) A Comparative Study of a Project-Based Course: Face to Face and Online, Florida State University. Selected Research and Development Papers Presented at The National Convention of the Association for Educational Communications and Technology Sponsored by the Research and Theory 
Division

Dallas

Available

at:https://www.tresystems.com/proceedings/documents/2002_dallas_volume1.pdf

[Accessed 14July 2020]

[3]. D.Olcum, O. Titrek, "The effect of School Administrators' Decision making Styles on Teacher Job Satisfaction",7th World Conference on Educational Sciences". (2015),Novotel Athens Convention Center,Athens,Greece,1936-1944

Available at:https://www.sciencedirect.com/science/article/pii/S1877042815045942

[Accessed 14 July 2020]

[4]. Edge, W.D. and Loegering, J.P. 'Distance Education: Expanding Learning Opportunities'. (2000) Wildlife Society Bulletin, 28(3):522-533.

[5]. Garrison, D. R. (1989). Understanding Distance Education: A Framework for the Future. London: Routledge, 198.

[6]. Glasow, P. A. (2005). Fundamentals of survey research methodology

Available

at:

http://www.mitre.org/work/tech_papers/tech_papers_05/05_0638/05_0638.pdf

[Accessed July 2020]

[7]. Harper K.C., Kimberly, C., Chen K., Yen, D. C. (2004). Distance learning, virtual classrooms, and teaching pedagogy in the Internet environment. Technology in Society, 26, 585-598.

[8]. Kerka, S. 'Deterrents to Participation in Adult Education' 1986 ERIC Digest No. 59, ED275889

[9]. Meacham, D. \& Evans, D. 'Distance Education: The Design of Study Materials'. Journal of Higher Education 44:1989, 661-679.

[10]. Nick O'Leary, Nicole Wattison, Toni Edwards and Kate Bryan,(2014) "European Physical Education students' use of jigsaw learning in a secondary school"

Available at:

https://www.researchgate.net/profile/Nick_OLeary/publication/267210835_Closing_th e theory-

practice gap_physical_education_students'_use_of_jigsaw_learning_in_a_secondary_s chool/links/5447caba0cf2d62c30513017/Closing-the-theory-practice-gap-physicaleducation-students-use-of-jigsaw-learning-in-a-secondary-school.pdf

[Accessed 1 July 2020]

[11]. Rekkedal, T. 1985. 'Introducing the Personal Tutor/counsellor in the System of Distance Education'. Project report 2: Final report. NKI, Stabekk, Norway.

[12]. Sewart, D. 'Continuity of Concern for Students in a System of Learning at a Distance'. ZIFF-Paper 22:1978, FernUniversity, Hagen.

[13]. Sewart, D. (1980). Creating an Information Base for an Individualized Support System in Distance Education. Distance Education 1(2):1980, 171-187.

[14]. Tuckman, B. W. (1999). Conducting Educational Research (5th ed.). Fort Worth, TX: Harcourt Brace.

[15]. Wood,H.(1996). 'Designing Study Materials for Distance Students’.

Available at:

http//www.csu.edu.au/division/oli/oli-rd/occpap17/design.htm

[Accessed 21 July 2020]

[16]. https://www.researchgate.net/publication/327396235_Distance_learning_virtual_classr ooms_and teaching_pedagogy_in_the internet_environment/citation/download 
[Accessed 28 July 2020]

[17]. https://www.peardeck.com/googleslides

[18]. https://en.unesco.org/covid19/educationresponse/solutions

[Accessed 25

June 2020] 